\title{
A Comparison of Linear Models for Estimating Co-Variance Components and Genetic Parameters in Holstein Dairy Cattle
}

\author{
Shalaby, N. A. ${ }^{1}$; S. A. Moawed $^{2 *}$ and K. M. El-Bayomi ${ }^{2}$ \\ ${ }^{1}$ Department of Animal Production, Faculty of Agriculture, Mansoura University, Egypt. \\ ${ }^{2}$ Department of Animal Wealth Development, Faculty of Veterinary Medicine, Suez Canal University, Ismailia, Egypt. \\ ${ }^{3}$ Department of Animal Wealth Development, Faculty of Veterinary Medicine, Zagazig University, Zagazig, Egypt.
}

\section{Received: 20/9/2015}

\begin{abstract}
The objective of this study was to compare four different statistical models for genetic evaluation of some traits of Holstein-Friesian dairy cattle raised in Egypt. Data were collected from Alexandria Copenhagen Company; a commercial dairy herd located in Egypt on Cairo-Alexandria desert road, and represented 2846 first three lactation records pooled from cows having 60 sires and 428 dams. The studied traits were; days open (DO), 305-days milk yield (305-DMY), fat yield (FY) and protein yield (PY). Models were discriminated according to random effects fitted in each model. The random effects were; direct additive genetic effects of animals, maternal additive genetic effects, permanent environmental effects, together with the covariance between direct and maternal genetic effects, and residuals. Comparisons of statistical models were based on (AG) Log Likelihood values and estimates of genetic parameters of traits. Co-variance components and genetic parameters were estimated with VCE-6 software package. Heritabilities obtained from all models were ranged from (0.07 to 0.10$),(0.24$ to 0.32$),(0.25$ to 0.42$)$ and $(0.24$ to 0.33$)$ for DO, 305-DMY, FY and PY, respectively. Also, for all traits, the best-fitted model was characterized by the highest Log Likelihood value, the highest maternal heritability and the existence of direct-maternal genetic covariance. Estimated breeding values (EBVs) showed high variations with positive spearman's rank correlations $(\geq 0.83)$ among models. This study showed that the inclusion of maternal effects with direct-maternal genetic covariances in the statistical models for genetic evaluations would improve the current herd genetically.
\end{abstract}

Keywords: Statistical models, heritability, model selection, Log Likelihood values.

\section{INTRODUCTION}

Genetic evaluation of dairy cattle is influenced by a variety of factors such as additive genetic, maternal genetic and permanent environmental effects. Different studies made evidence that fitting a model with maternal effects would lead to a more precise estimation of (co)variance components and subsequently genetic parameters of both productive and reproductive traits of dairy cows (Miraei-Ashtiani et al., 2007; Zamani and Mohammadi, 2008; Mohammadi et al., 2013 and JalilSarghale et al., 2014). As a result, designing breeding programs and genetic evaluation systems require the use of more precise estimation of variance components and genetic parameters by adopting the best statistical models.

Unbiased animal model ranking for identification of genetic merit of individual animals need us to develop an operational model closer to the biological one considering recent advances computational capabilities. It is therefore, the search for the most suitable statistical model and the furthermost advanced statistical tool is an important step in the development of genetic improvement schemes. Hence, the quality of the statistical models adopted for genetic evaluations of herd animals must be checked against other available models before being used in genetic evaluation procedures. Setting up a good statistical model is an essential concern for a reliable genetic computation and evaluation (Jorjani, 2003).

Recent model diagnostics and criteria could be used in evaluating the validity of statistical models to fit the best model among competitive ones. The most recent and familiar tools are; Akaike information criterion (AIC), the Schwarz Bayesian information criterion (BIC), and the $-2 \log$ likelihood (Log L). Hence, the present study aimed to compare four statistical models based on AG Log likelihood values. In addition, to fit different models including additive genetic, maternal additive and permanent environmental effects for choosing the most appropriate statistical model to be largely used in genetic evaluation of dairy cattle herds.

\section{MATRIALES and METHODS}

\section{Data collection and herd management}

Data of the current study were collected from Alexandria Copenhagen Company, a commercial dairy herd located in Cairo-Alexandria desert road, about 80 $\mathrm{km}$ from Alexandria, Egypt. On the farm, all animals were kept in an open system under open sheds allover the year round, however supplied with a cool spraying system during hot climate. Animals had free access to clean water. The cows were fed on total mixed ration (T.M.R.) according to their production status. The ingredient compositions of rations were formulated through nutrient requirements of dairy cattle recommended by the National Research Council (NRC, 2001). Cows were machine-milked three times daily with 8 hours interval (at 6.00, 14.00 and 22.00 o'clock) in a herringbone parlor Alfa Lafal (40 point). Recording system used in the farm was a computer program system (Afikim and Dairy Comb 305). Heifers were inseminated when they reached an average of about 350 $\mathrm{kg}$ body weight. Inseminations were done artificially using frozen semen from the best 100 Total Predicted Index (TPI) Holstein bulls in U.S.A. and Canada assuming some reproductive and productive traits for Holstein-Friesian dairy cows. The studied traits were; 
days open (DO), 305-days milk yield (305-DMY), fat yield (FY), and protein yield (PY). The data used represented 2846 lactation records of cows with 60 sires and 428 dams, and born in the period from 2000 to 2010. Data were pooled for the first three lactations before analysis to construct repeated lactations for the permanent environmental effects and variance components estimation.

\section{Statistical models fitting}

Mixed linear models were used in all analyses applied in the present study. The fixed effects of models incorporated age at first calving (years), year of calving (from 2000 to 2010), season of calving (winter, spring, summer, and autumn). The random effects varied according to the model used for analysis. Animal, dam, and sires were fitted in all models. Variance components and genetic parameters for the investigated traits were estimated by VCE software, version 6.0.2 according to Groeneveld et al. (2008). Four models were used, and identified by two criteria; the first is the presence or absence of maternal genetic and permanent environmental effects; while the second is the existence or non-existence of direct- maternal additive genetic covariance. Model (1) was the least full animal model where only the additive genetic effect was fitted as the sole random effect of the model together with the residuals. Model (2) was increased by adding the permanent environmental effect as another random effect. Model (3) was adjusted to be as model (2), but the permanent environmental effect was replaced with maternal effects as a random effect, with the existence of direct-maternal genetic covariance. Model (4) was fitted to include three main random effects; additive genetic, maternal and permanent environmental effects, with the inclusion of direct-maternal genetic covariance. The tested models in matrix notation were as follows:

Model 1, was a full animal model:

$$
\mathrm{Y}=\mathrm{X} \beta+\mathrm{Z}_{1} \mathrm{a}+\mathrm{e}
$$

Model 2, was a full animal model together with only maternal permanent environmental effects:

$$
\mathrm{Y}=\mathrm{X} \beta+\mathrm{Z}_{1} \mathrm{a}+\mathrm{Z}_{2} \mathrm{C}+\mathrm{e}
$$

Model 3, was a full animal model with maternal additive genetic effects, but correlated with additive genetic one:

$$
\mathrm{Y}=\mathrm{X} \beta+\mathrm{Z}_{1} \mathrm{a}+\mathrm{Z}_{3} \mathrm{~m}+\mathrm{e}, \quad \operatorname{Cov}(\mathrm{a}, \mathrm{m})=\mathrm{A} \sigma_{\mathrm{a}, \mathrm{m}}
$$

Model 4, was a full animal model with maternal additive genetic and permanent environmental effects, but both direct additive and maternal effects were uncorrelated:

$$
\mathrm{Y}=\mathrm{X} \beta+\mathrm{Z}_{1} \mathrm{a}+\mathrm{Z}_{2} \mathrm{C}+\mathrm{Z}_{3} \mathrm{~m}+\mathrm{e}, \quad \operatorname{Cov}(\mathrm{a}, \mathrm{m})=0
$$

Where, $\mathrm{Y}$ is the vector of observations of studied traits; $\beta, \mathrm{a}, \mathrm{C}, \mathrm{m}$, and e are the vectors of the fixed effects, animals additive genetic effects of, permanent environmental effects of dams of repeated lactations, maternal additive genetic effects, and residual effects, respectively. $X, Z_{1}, Z_{2}$, and $Z_{3}$ are the incidence matrices of the fixed effects, additive genetic effects of animals, permanent environmental effects of dams, and maternal additive genetic effects, respectively.

(Co) variance components were found to be as follows: $\mathrm{V}(\mathrm{a})=\mathrm{A} \sigma_{\mathrm{a}}^{2}, \mathrm{~V}(\mathrm{~m})=\mathrm{A} \sigma_{\mathrm{m}}^{2}, \mathrm{~V}(\mathrm{c})=\sigma_{\mathrm{c}}^{2} \mathrm{I}, \mathrm{V}(\mathrm{e})=\sigma_{\mathrm{e}}^{2} \mathrm{I}$ $\operatorname{Cov}(\mathrm{a}, \mathrm{m})=\mathrm{A} \sigma_{\mathrm{a}, \mathrm{m}}$ for $\operatorname{Model}(3)$.
The following is a general formula for the (co)variance components in matrix notation:

$$
\mathrm{V}\left(\begin{array}{l}
\mathbf{a} \\
\mathbf{m} \\
\mathbf{c} \\
\mathbf{e}
\end{array}\right)=\left(\begin{array}{cccc}
\mathbf{A} \sigma^{2}{ }_{\mathrm{a}} & \mathbf{A} \sigma_{\mathrm{am}} & \mathbf{0} & \mathbf{0} \\
\mathbf{A} \sigma_{\mathrm{am}} & \mathbf{A} \sigma^{2}{ }_{\mathrm{m}} & \mathbf{0} & \mathbf{0} \\
\mathbf{0} & \mathbf{0} & \mathrm{I} \sigma_{\mathrm{c}}^{2} & \mathbf{0} \\
\mathbf{0} & 0 & 0 & \mathrm{I} \sigma_{\mathrm{e}}^{2}
\end{array}\right)
$$

Where, $\sigma_{\mathrm{a}}^{2}$ is the additive genetic variance; $\sigma_{\mathrm{m}}^{2}$ is the maternal additive genetic variance; $\sigma^{2}$ is the variance of maternal permanent environmental effects (because dams may have more than offspring in data); $\sigma_{\mathrm{e}}^{2}$ is the residual variance; $\sigma_{\mathrm{a}, \mathrm{m}}$ is the covariance between direct and maternal additive genetic effects; while $\mathrm{A}$ is the numerator relationship matrix among animals and I is the identity matrix.

Also,

$$
\left(\begin{array}{l|l}
\mathbf{a} & \mathbf{A}, \mathbf{G} \\
\mathbf{m}
\end{array}\right) \sim \mathrm{N}
$$

$\left(\left(\begin{array}{l}\mathbf{0} \\ \mathbf{0}\end{array}\right), \mathrm{G} \otimes \mathbf{A}\right)$

Where,

$$
\mathrm{G}=\left(\begin{array}{cc}
\boldsymbol{\sigma}_{\mathbf{a}}^{2} & \boldsymbol{\sigma}_{\text {am }} \\
\boldsymbol{\sigma}_{\text {am }} & \boldsymbol{\sigma}_{\mathbf{m}}^{2}
\end{array}\right), \text { and }
$$

$\otimes$ is a direct product of matrix and,

$$
\mathbf{C} \sim \mathbf{N}\left(\mathbf{0}, \mathbf{I} \boldsymbol{\sigma}_{\mathrm{c}}^{2}\right)
$$

and,

$$
\mathbf{e} \sim \mathbf{N}\left(0, \mathbf{I} \sigma_{\mathrm{e}}^{2}\right)
$$

Additive and maternal heritabilities were estimated as follows:

$$
\mathrm{h}_{\mathrm{a}}^{2}=\frac{\boldsymbol{\sigma}_{\mathrm{a}}^{\mathbf{2}}}{\boldsymbol{\sigma}_{\mathrm{p}}^{2}}, \mathrm{~h}_{\mathrm{m}}^{2}=\frac{\boldsymbol{\sigma}^{2} \mathbf{m}}{\boldsymbol{\sigma}^{2} \mathbf{p}}
$$

Where, $\mathrm{h}_{\mathrm{a}}^{2}$ is the additive genetic heritability; $\mathrm{h}_{\mathrm{m}}^{2}$ is the maternal additive genetic heritability according to the equation of (Willham, 1980); $\boldsymbol{\sigma}^{2}{ }_{\mathbf{a}}, \boldsymbol{\sigma}^{2}{ }_{\mathbf{m}}$, and $\boldsymbol{\sigma}_{\mathbf{p}}{ }^{2}$ are the corresponding variance components estimated by each model.

\section{RESULTS}

\section{Description of data}

Summary of data used in the present study including number of records, overall means, standard deviations, minimum, maximum, and coefficients of variation of traits were presented in Table (1). Overall means of days open, 305 days milk yield, fat yield, and protein yield were; 166.02 days, $8478.59 \mathrm{~kg}, 267.92 \mathrm{~kg}$, and $221.56 \mathrm{~kg}$, respectively. In addition, standard deviations were estimated for these traits to be 124.64 days, $2333.84 \mathrm{~kg}, 102.78 \mathrm{~kg}$, and $84.92 \mathrm{~kg}$, respectively. The current data showed high variations of most of studied traits, which were ensured by the minimum and maximum values. Moreover, coefficients of variations were high especially for days open trait $(75.07 \%)$. 
Table (1): Summary statistics for studied traits of the first three pooled lactations

\begin{tabular}{ccccccc}
\hline Trait studied & Number & Mean & SD & Minimum & Maximum & C.V.\% \\
\hline Days open, days & 2846 & 166.02 & 124.64 & 19.00 & 965.0 & 75.07 \\
305-days milk yield, kg & 2846 & 8478.59 & 2333.84 & 524.00 & 16276.0 & 27.53 \\
Fat yield, kg & 2846 & 267.92 & 102.78 & 9.00 & 594.0 & 38.36 \\
Protein yield, kg & 2846 & 221.56 & 84.92 & 7.00 & 529.0 & 38.33 \\
\hline
\end{tabular}

SD is standard deviation; C.V. \% is the coefficient of variation

\section{Variance components and genetic parameters estimates}

Table (2) shows the estimates of (co) variance components and heritabilities with their standard errors of the four traits as estimated from different tested models. Generally, estimates of variance components and heritabilities varied for all traits by the model. Estimates of additive genetic variances of days open were 1377, 1095, 1402, and $1317 \mathrm{day}^{2}$; of 305-days milk yield were 1378691, 1251960, 1536717, and $1310311 \mathrm{~kg}^{2}$; for fat yield were $2974,2522,3593$, and $2859 \mathrm{~kg}^{2}$; for protein yield were $1692,1401,1967$, and $1605 \mathrm{~kg}^{2}$ as resulted from Model 1 through 4, respectively. These results showed that the highest additive genetic variances were attained from Model 3 for all traits (where the covariance between maternal effects exists).

Maternal variance components were estimated only in Models 3 and 4, but turned to become continuously higher in Model 3 for all traits. The estimates from Model 3 for days open, 305-day milk yield, fat yield, and protein yield were 612 day $^{2}, 362731$ $\mathrm{kg}^{2}, 708 \mathrm{~kg}^{2}$, and $434 \mathrm{~kg}^{2}$, respectively. On the other hand, estimates of maternal additive variances for Model 4 were relatively smaller and were 0.120 day $^{2}$, $32464.8 \mathrm{~kg}^{2}, 7.6 \mathrm{~kg}^{2}$, and $24.9 \mathrm{~kg}^{2}$, respectively for the same traits, respectively.

The permanent environmental variances as fitted in Model 2 and Model 4 were higher in Model 2 (where the maternal additive effects were absent) than Model 4. The component values were $326 \mathrm{day}^{2}, 147360 \mathrm{~kg}^{2}, 387$ $\mathrm{kg}^{2}$, and $236 \mathrm{~kg}^{2}$ in Model 2 for days open, milk yield, fat yield, and protein yield, respectively. The estimates for the same traits were $34.2 \mathrm{day}^{2}, 35095 \mathrm{~kg}^{2}, 43.4 \mathrm{~kg}^{2}$, and $36 \mathrm{~kg}^{2}$ in Model 4. The present results showed also a negative covariances and correlations between additive and maternal effects in Model 3 for all tested traits. The direct-maternal genetic correlations were moderate to high and ranged from $(-0.66)$ to $(-0.87)$.

In the current study, estimates of phenotypic variances and ratios of permanent environmental variances to phenotypic variances were found to be slightly different from model to another. The differences were observed to be of the same magnitude for all the four traits, as presented in Table (2). In addition, the estimates of heritabilities were varied by the tested model. It was noticed that the greatest heritabilities for all traits were reported in Model 3. More detailed, heritabilities within range were $(0.078-0.104),(0.241-$
0.329), (0.259-0.429), and (0.214-0.335) for days open, 305-days milk yield, fat yield, and protein yield, respectively. Thus, maternal heritabilities were higher in Model 3 than in Model 4 for all studied traits. The highest maternal heritability was for fat yield (0.085) which was very small as compared to heritability. Maternal heritabilities of days open, 305-days milk yield, and protein yield in Model 3 were 0.045, 0.078, and 0.074 , respectively.

\section{Estimated Breeding Values of Traits}

Standard deviations, minimum, maximum, and range of estimated breeding values (EBVs) are listed in Table (3). These estimates were used to study the effect of statistical models on their values. Among tested models, there were high variations in the values of breeding values of animals for productive and reproductive traits. The range of EBVs of days open and protein yield were the highest in Model 1, while the range of EBVs of 305-day milk yield and fat yield were the highest in Model 3 as compared to other models. The results of days open in Model 1 showed EBVs that ranged from - 65.06 day to 103.42 day, while those of protein yield from the same model were ranged from $93.13 \mathrm{~kg}$ to $116.14 \mathrm{~kg}$. In addition, 305-day milk yield and fat yield as a main productive traits, reported EBVs in Model 3 with a range of (-993.8 kg to $3211.7 \mathrm{~kg})$, and $(-116.08 \mathrm{~kg}$ to $169.5 \mathrm{~kg})$, respectively.

Furthermore, to test the reliability of the four models, spearman's rank correlations among estimated breeding values obtained by different models are given in (Table 4). The results showed a high positive and significant $(\mathrm{P} \leq 0.05)$ spearman's rank correlations $(\geq$ 0.83 ) among EBVs of studied traits in different models.

\section{Models comparison and ranking}

The present paper demonstrated different four linear models for genetic assessment of dairy cattle. Hence, these models were compared to obtain the most reliable parameter and (co)variance component estimates for the same trait. Model comparison section as presented in (Table 5) was depended on the analytical gradient (AG) Log Likelihood function. Based on the VCE results, the AG Log $\mathrm{L}$ values were 7625.63, 7549.71, 10368.37, and 10297.02 for Models 1, 2, 3, and 4, respectively. Models were ranked from the highest to the smallest Log $\mathrm{L}$ values. It was noticed that Model 3 was the highest, while Model 2 was the lowest in $\log \mathrm{L}$ values. 


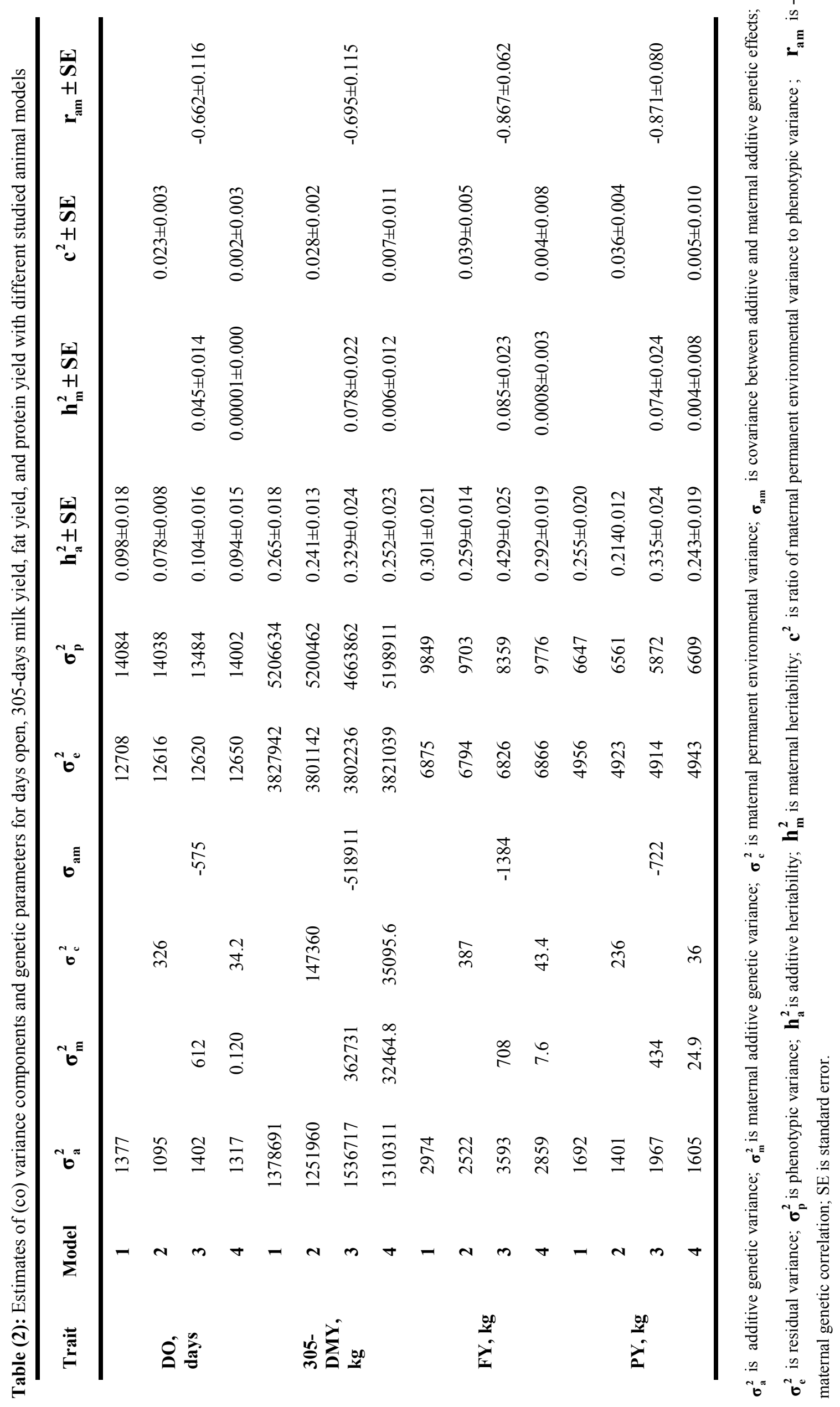


Table (3): Standard deviation (SD), minimum, maximum, and range of estimated breeding values of traits:

\begin{tabular}{|c|c|c|c|c|c|}
\hline Model & Trait & SD & Minimum & Maximum & Range \\
\hline \multirow{4}{*}{ Model 1} & Day open, days & 17.45 & -65.06 & 103.42 & 168.48 \\
\hline & $305 \mathrm{DMY}, \mathrm{kg}$ & 549.63 & -993.90 & 3120.50 & 4114.50 \\
\hline & Fat yield, kg & 39.44 & -123.43 & 160.68 & 284.11 \\
\hline & Protein yield, kg & 28.39 & -93.13 & 116.14 & 209.26 \\
\hline \multirow{4}{*}{ Model 2} & Day open, days & 15.81 & -57.17 & 84.39 & 141.56 \\
\hline & $305 \mathrm{DMY}, \mathrm{kg}$ & 548.10 & -997.50 & 2893.30 & 3890.80 \\
\hline & Fat yield, $\mathrm{kg}$ & 35.38 & -109.61 & 144.96 & 254.56 \\
\hline & Protein yield, kg & 26.00 & -81.37 & 105.36 & 186.74 \\
\hline \multirow{4}{*}{ Model 3} & Day open, days & 18.63 & -60.50 & 81.54 & 142.05 \\
\hline & 305 DMY, kg & 583.90 & -993.80 & 3211.70 & 4205.50 \\
\hline & Fat yield, $\mathrm{kg}$ & 39.34 & -116.08 & 169.50 & 285.58 \\
\hline & Protein yield, kg & 29.34 & -85.51 & 117.63 & 203.14 \\
\hline \multirow{4}{*}{ Model 4} & Day open, days & 18.15 & -63.84 & 99.41 & 163.25 \\
\hline & $305 \mathrm{DMY}, \mathrm{kg}$ & 566.80 & -979.50 & 2974.80 & 3954.30 \\
\hline & Fat yield, kg & 38.42 & -118.96 & 158.41 & 277.38 \\
\hline & Protein yield, kg & 28.41 & -88.60 & 114.44 & 203.04 \\
\hline
\end{tabular}

Table (4): Spearman rank correlations among EBVs for all studied traits from different models

\begin{tabular}{|c|c|c|c|c|c|c|}
\hline \multirow{2}{*}{ Models } & \multicolumn{3}{|c|}{ Days open } & \multicolumn{3}{|c|}{ 305-days milk yield } \\
\hline & Model 1 & Model 2 & Model 3 & Model 1 & Model 2 & Model 3 \\
\hline Model 2 & $0.99^{* *}$ & & & $0.98^{* *}$ & & \\
\hline Model 3 & $0.83^{*}$ & $0.85^{*}$ & & $0.89^{* *}$ & $0.89^{*}$ & \\
\hline \multirow[t]{2}{*}{ Model 4} & $1.00^{*}$ & $0.99^{* *}$ & $0.84^{* *}$ & $0.99^{* *}$ & $0.98^{* *}$ & $0.90^{* *}$ \\
\hline & \multicolumn{3}{|c|}{ Fat yield } & \multicolumn{3}{|c|}{ Protein yield } \\
\hline Model 2 & $0.99^{* *}$ & & & $0.99^{* *}$ & & \\
\hline Model 3 & $0.90^{*}$ & $0.90^{* *}$ & & $0.91^{*}$ & $0.91^{* *}$ & \\
\hline Model 4 & $1.00^{* *}$ & $1.00^{* *}$ & $0.90^{* *}$ & $1.00^{* *}$ & $1.00^{* *}$ & $0.91^{* *}$ \\
\hline
\end{tabular}

* Significant $(\mathrm{P} \leq 0.05)$.

** Highly significant $(\mathrm{P} \leq 0.01)$.

Table (5): Model rank based on the value of AG Log likelihood for model selection:

\begin{tabular}{|c|c|c|c|}
\hline Model & Effects & Rank & $\begin{array}{c}\text { AG Log likelihood } \\
\text { values * }\end{array}$ \\
\hline 1 & Only additive genetic & 3 & 7625.6300 \\
\hline 2 & Additive genetic with permanent environmental & 4 & 7549.7149 \\
\hline 3 & Additive genetic, maternal and covariance & 1 & 10368.3710 \\
\hline 4 & $\begin{array}{l}\text { Additive genetic, maternal, and permanent environmental (without } \\
\text { covariance) }\end{array}$ & 2 & 10297.02 \\
\hline
\end{tabular}

\footnotetext{
$* \mathrm{AG}=$ the resultant of multiplying the relationship, $\mathrm{A}$ by genetic, $\mathrm{G}$ matrices)

* Log Likelihood values ( $\log \mathrm{L})$ for goodness of fit of the adopted statistical model
} 


\section{DISCUSSION}

The present study showed large coefficients of variation with a range of (38-75\%) for most of studied traits, especially days open then milk composition traits. These values may indicate a wide variation among animals of the current herd. Mostafa et al. (2013) conducted a similar study on Holstein-Friesian dairy herd. They revealed $40 \%$ as C.V for milk yield trait, and concluded that the high C.V. Percent may reflects a great variation between individuals.

The additive genetic variance as the common random effect in all models was fluctuating from model to another for milk yield traits. The present components were higher than those reported by many authors such as; Schutz et al. (1992) in USA; Olori et al. (2002) in Ireland; Adel et al. (2005) on the Friesian cows in Egypt; Edriss et al. (2006) on Holstein Friesian cows in Iran; and Mostafa et al. (2013) on the Egyptian native cows. These results indicate that the variance components may be affected by the characteristics of populations, herd structures and sample size. In addition, they depended on the statistical model used in analysis.

Based on the present results, both additive and maternal heritabilities of all traits were changed and affected by the random effects included in the model. It was found that the stepwise changes among maternal effects, permanent environmental effects, and the covariances between additive and maternal effects caused a fluctuation in heritability estimates. Additive heritabilities were observed with the greatest increase for all studied traits in Model 3 (where the maternal additive genetic effects were fitted in the models, together with the existence of -maternal genetic covariances). In contrast to the present findings, Mostafa et al. (2013) estimated narrow sense heritabilities from a full animal model (including; additive, maternal and maternal genetic covariances) for 305-DMY, fat yield and protein yield to be $0.33,0.16$ and 0.64 , while from the model without maternal effects they were $0.34,0.17$ and 0.65 for the same traits. Mostafa et al. (2013) concluded that the removal of maternal effects and the direct-maternal genetic covariances from the model increased the estimates of narrow sense heritabilities (heritability in the narrow sense). Similar conclusion was reported by Albuquerque et al. (1998) who indicated that narrow sense heritabilities increased by 0.014 and 0.021 for milk and fat yields when the these effects were removed from the model. Nevertheless, the present estimates of narrow sense heritabilities of 305-DMY are within the range of Albuquerque et al. (1998), Yener et al. (2006), Usman et al. (2012), and Mostafa et al. (2013), but higher for fat and lower for protein yield. Different authors such as; Weigel et al. (1999), and Edriss et al. (2006) estimated narrow sense (additive) heritability for milk and fat yield to be $(0.320$ and 0.205$)$; $(0.23$ and 0.17$)$, respectively, from a model with only additive genetic effects.

Although, maternal heritabilities of this study were relatively small, but they increased by inclusion of direct-maternal genetic covariance (from model 4 to 3 ) and the exclusion of permanent environmental effects from the statistical model. This result is in disagreement with the findings of Schutz et al. (1992), Albuquerque et al. (1998) and Edriss et al. (2006), but accordance with the results obtained by Zülkadirs et al. (2009). On the other hand, the direct-maternal genetic covariances, and correlations estimated by Model 3 were all negative with moderate to high values, which suggest the inverse relationship between additive and maternal effects, and may play a role in the improvement of maternal heritabilities from Model 4 to Model 3. Different studies also recorded a negative correlation between additive and maternal additive genetic effects, such as Lee et al. (2003) to be -0.45; Adel et al. (2005) to be -0.45; Mostafa et al. (2013) to be -0.58. Other studied conducted by Albuquerque et al. (1998) and Edriss et al. (2006) recorded a positive correlation and covariances between additive and maternal effects.

Animal's breeding values (BVs) were high for all traits of the present study, which indicate that the genetic difference among individuals is a factor, which reflects the rate of expected genetic improvement that can be accomplished through individual selection. Breeding values of 305-day milk yield, fat and protein yield of the present study are somewhat higher than those estimated by Zutere (2008) and Ayied et al. (2011), and lower those reported by Mosharraf et al. (2014) except for milk yield trait. The high variances and ranges of BVs estimated by different models may indicate that these models gave a reasonable goodness of fit and accuracy for selection and genetic improvement of the current traits. Moreover, spearman rank correlations between estimated breeding values from the four models were high and positive ( $\geq 0.83$ ). These correlations are higher than the findings of Cilek and Kaygisiz (2008) and Kaygisiz (2013) and similar to those reported by Kaya et al. (2003) and Seyedsharifi et al. (2008). Spearman rank correlations $(\geq 0.97)$ obtained by Kaya et al. (2003) and Zutere (2008) indicate that for all studied traits, ranking of animals according to their estimated breeding values was closely correlated with each other and are in accordance with the present findings.

Model comparisons in the present investigation are mainly dependent on the values of the Log Likelihood of $\mathrm{AG}$ (i.e. the resultant of multiplying the relationship by genetic matrices) and the effect of model structure on the estimates of both (co)variance components and corresponding heritabilities. Many studies have shown that a higher Log Likelihood values ( $\log$ L) for goodness of fit of statistical model are preferable. For instance, Edriss et al. (2006) mentioned that animal models with higher Log Likelihood values are more accurate and concluded that by considering more parameters in the models, there would be more improvement for the animal models accuracy. In addition, Miroslav and Marija (2004) concluded that the best-fit model should have highest log likelihood and smallest 'Mendelian sampling' standard deviation. Furthermore, Posta et al. (2009) used VCE software for variance components estimation in sport horse; they mentioned that the model with the highest loglikelihood value was considered as the best fitting 
model. On this basis, Model 3 with the highest AG Log $\mathrm{L}$ is considered the best-fit model for genetic evaluation of the current traits, followed by Model 4 then Model 1 and Model 2. Comparing Models 2, 3 and 4 versus Model 1 based on model structure and the impact of maternal effects, permanent environmental effects and the maternal additive genetic covariance, it was found that the presence of only maternal genetic effect (in Model 3) lead to increase in additive genetic variance and narrow sense heritabilities for all traits. On the other hand, when both maternal effects and permanent environmental effects fitted together (in Model 4), the result is the decrease in values of additive genetic variance and heritabilities as compared to Model 3. In addition, the inclusions of only permanent environmental effect (in Model 2) lead to the same result of decrease in estimates as occurred in Model 4. From these results, we can conclude that the existence of -maternal genetic covariance in Model 3, which included maternal additive genetic effects as the only random effect together with the additive one, resulted in the greatest increase in additive genetic variance and additive heritability estimates. Variety of studies such as those reported by Schutz et al. (1992), Albuquerque et al. (1998), Khattab et al. (2005), Edriss et al. (2006) and Mostafa et al. (2013) concluded that the inclusion of maternal effects in the model resulted in reduction in estimates of additive genetic variances and heritabilities especially for milk traits. In contrast to these findings, the present study showed that if the model was fitted with maternal effects together with the -maternal genetic covariance, this might improve the estimates of variance components and both additive and maternal heritability for studied traits. The moderate to high and negative correlations between direct and maternal effects and their negative covariances for all traits indicate the existence of negative relationship between additive and maternal additive genetic effects. In other words, selection on the base of animal's milk yield will subsequently decrease the maternal performance. Similarly, Tawah et al. (1993) reported that the negative correlations between additive and maternal effects may reflect the adaptation of animals to a dry tropical environment. In addition, negative direct and maternal genetic correlations may suggest that both additive and maternal effects could be selected for breeding programs.

Moreover, both Models 2 and 4 included the permanent environmental effects, which were not clear in this study, as the ratio of permanent environmental variances to the total phenotypic variances were small and may have non-significant contribution in improvement of heritabilities as compared with Model 3. This may be attributed to the fact that the present data included only the first three lactations with small number of records; hence, the permanent environmental effect may appear much effectively, if more repeated records were used.

\section{CONCLUSION}

One of the most significant and effective applications of statistics in animal breeding is to provide and fit a more accurate and applied models for estimating genetic parameters in dairy cattle. The present study demonstrates some criteria for evaluating four statistical models with different structures. A comparison between AG Log Likelihood values, (co) variance components, heritability estimates revealed that Model 3 in this study was the best and suitable model for genetic improvement of the current herd. The moderate heritabilities of studied traits suggest the importance of these traits in selection programs and good practices. The results showed that the inclusion of maternal additive genetic effects with additive genetic effects together with the covariance between them give the best estimates rather than using the model with permanent environmental effects or the absence of direct-maternal genetic covariance. In addition, the negative correlations and covariances between direct and maternal effects could probably have indirect contribution in genetic improvement of dairy farms with attention to number of records and number of daughters per dam, because the maternal heritability increased in the presence of these effects in the model. Moreover, the permanent environmental effects may be effective and reasonable if later lactations could be used in further investigation.

\section{ACKNOWLEDGMENTS}

The authors would like to express the great appreciation to Eildert Groeneveld for kindly providing the free computer program software (VCE-6), which was used in the present study for data analysis.

\section{REFERENCES}

Adel, S.K., A. Hulya and B. Lila (2005). Variances of additive and maternal effects for milk yield and age at first calving in a herd of Friesian cattle in Egypt. Arch. Tierz., Dummerstorf, 48(1): 24-31.

Albuquerque, L.D., J. F. Keown and L. D. Van-Vleck (1998). Variances of additive genetic effects, maternal effects and cytoplasm inheritance effects for milk yield, fat yield and Fat percentage. J. Dairy Sci., 81: 544- 549.

Ayied, S.A., A. J. Jadoa and A. J. Abdulrada (2011) Heritabilties and breeding values of production and reproduction traits of Holstein cattle In Iraq. J. Basrah Res. (Sciences), 37: 66-70.

Çilek, S. and A. Kaygisiz (2008). Breeding Value Estimation of Dairy Cattle Using Test Day Milk Yields for Brown Swiss Cows Reared at Ulaş State Farm. J Anim. Vet. Adv., 7(6): 703-706.

Edriss, M.A., M. A. Nilforooshan and J. M. Sadeghi (2006). Estimation of direct genetic and maternal effects for productive traits of Iranian Holstein cows using different animal models. Pakistan Journal of Biological sciences, 9(4): 636-640.

Groeneveld, E., M. Kovac and N. Mielenz (2008). VCE User's Guide and Reference Manual, Version 6.0 Institute of Farm Animal Genetics, Mariensee, Germany.

Jalil-Sarghale, A., M. Kholghi, M. MoradiShahrebabak, H. Moradi-Shahrebabak, H. Mohammadi and R. Abdollahi-Arpanahi (2014). Model comparisons and genetic parameter 
estimates of growth traits in Baluchi sheep. Slovak J. Anim. Sci., 47(1): 12-18.

Jorjani, H. (2003). An overview of validation issues in national genetic evaluation systems (N-GES). Interbull Bulletin, 30: 49-58.

Kaya, I., Y. Akbas Y. and C. Uzmay (2003). Estimation of breeding values for dairy cattle using test-day milk yields. Turk J. Vet. Anim. Sci., 27: 459-464.

Kaygisiz, A. (2013). Estimation of genetic parameters and breeding values for dairy cattle using test-day milk yield records. The journal of animal and plant sciences, 23(2): 345-349.

Khattab A.S., H. Atil and L. Badawy (2005). Variances of direct and maternal genetic effects for milk yield and age at first calving in a herd of Friesian cattle in Egypt. Arch. Tierz. Dummerstorf, 48: 2431.

Lee, D.H., K.J. Han and B.H. Park (2003). Genetic relationship between milk yields, calving ease and days open at first lactation of Holstein cows in Korea. Interbull Bull. 31: 122-129.

Miraei-Ashtiani, S.R., S.A.R. Seyedalian, and M. Moradi-Shahrbabak (2007). Variance components and heritabilities for body weight traits in Sangsari sheep using univariate and multivariate animal models. Small Ruminant Research, 73: 109-114.

Miroslav, K. and S. Marija (2004). Estimation of genetic parameters and breeding values of milk traits for Simmental cattle in Croatia using a Lactation animal model. Agriculturae Conspectus Scientificus, 69(4): 91-94.

Mohammadi, H., M. Moradi-Shahrebabak, H. MoradiShahrebabak, A. Bahrami and M. Dorostkar (2013). Model comparisons and genetic parameter estimates of growth and the Kleiber ratio in Shal sheep. Archiv Tierzucht 56 (26), 264-275.

Mosharraf, R., J. Shodja, M. Bohlouli, S. Alijani and S. A. Rafat (2014). Estimation of (co)variance components and breeding values for test-day milk production traits of holstein dairy cattle via bayesian approach. Biotechnology in Animal Husbandry, 30(1): 15-28.

Mostafa, M.A., E.A. Beder, A.S. Khattab and J. Tözser (2013). Variances of direct and maternal genetic effects for milk yield and its composition in a herd of Friesian cows in Egypt. Animal welfare, ethology and housing systems (AWETH), 9(3): 26-31.

National Research Council (2001). Nutrient requirements of dairy cattle. $7^{\text {th }}$ rev. ed. Natl. Acad. Sci., Washington, DC.
Olori, V.E., T.H.E. Meuwissen and R.F. Veerkamp (2002). Calving Interval and Survival Breeding Values as Measure of Cow Fertility in a PastureBased Production System with Seasonal Calving. Journal of Dairy Science, 85(3): 689-696.

Posta, J., S. Mihok, S. Markus and I. Komlosi (2009). Analysis of Hungarian sport horse show jumping results using different transformations and models. Archiv Tierzucht, 52(5): 451-458.

Schutz, M.M., A.E. Freeman, D.C. Beitz and J.E. Mayfield (1992). The importance of maternal lineage on milk yield traits of dairy cattle. J. Dairy Sci., 75: 1331-1341.

Seyedsharifi, R., M.P.E. Nasab and A. Sobhani (2008). Estimation of Genetic Parameters and Breeding values for Test-day and 305-days Milk Yields in Some Iranian Holstein Herd. J. Anim. Vet. Adv., 7(11): 1422-1425.

Tawah, C.L., D.A. Mbah, J.E.O. Rege and H. Oumate (1993). Genetic evaluation of birth and weaning weights of Gudali and two-breed synthetic Wakwa beef cattle populations under selection in Cameroon: genetic and phenotypic parameters. Anim. Prod., 57: 73-79.

Usman, T., G. Guo, S.M. Suhail and Y. Wang (2012). Performance traits study of Holstein Friesian cattle under subtropical conditions. J. of Animal and Plant Sci., 22: 92-95.

Weigel, K.A., T. Kriegl and A.L. Pohlman (1999). Genetic analysis of dairy cattle production traits in a management intensive rotational grazing environment. J. Dairy Sci., 82: 191-195.

Willham, R. (1980). Problems in estimating maternal effects. Liv. Prod. Sci., 7: 405- 418.

Yener, S.M., N. Akman, A.S. Khattab and A. Hussein (2006). Genetic aspecsts for productive reproductive traits for Friesian cows in Egypt. $57^{\text {th }}$ Annual meeting of the European Association for Animal Production, Antalya, Turkey.

Zamani, P. and H. Mohammadi (2008). Comparison of different models for estimation of genetic parameters of early growth traits in the Mehraban sheep. Journal of Animal Breeding and Genetics. 125: 29-34.

Zulkadir, U., I. Aytekin and A. Pala (2009). Genetic Analyses for Milk Yield, Lactation Period, and Fat Percentage in Brown Swiss Cattle. Journal of Animal and Veterinary Advances, 8: 857-862.

Zutere, R. (2008). Estimates of breeding values for dairy cattle using test-day milk yields. Latvian Journal of Agronomy, 10: 293-299. 
مقارنة بين النماذج الخطية المستخدمة في تقدير مكونات التباين والمعالم الوراثية لأبقار حلاب الهولشتين

ناظم عبد الرحمن شلبى1، شريف عبد الرحمن معوض، خيرى محمد البيومى 3

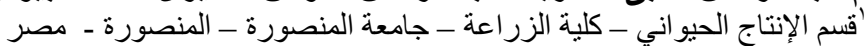

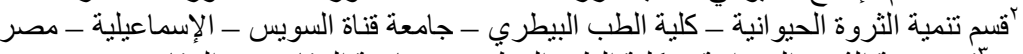

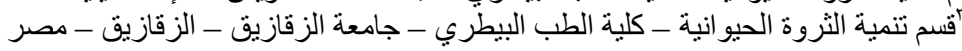

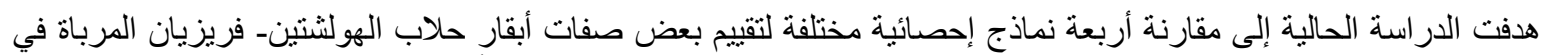

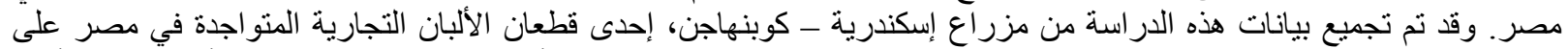

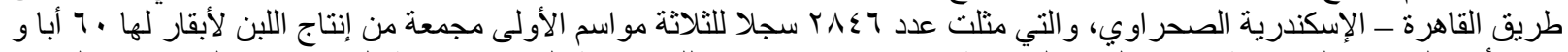

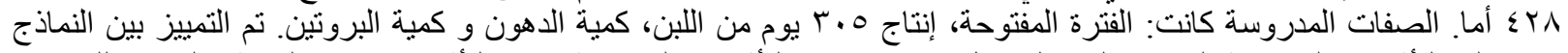

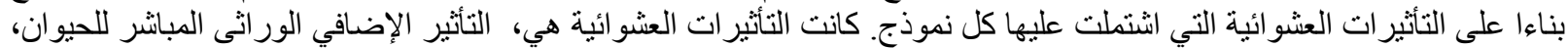

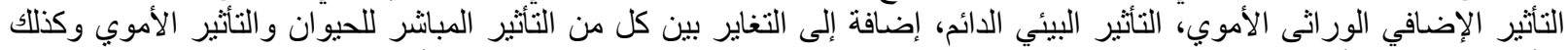

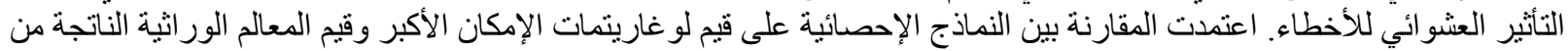

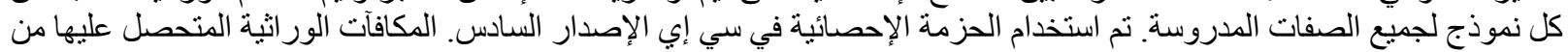

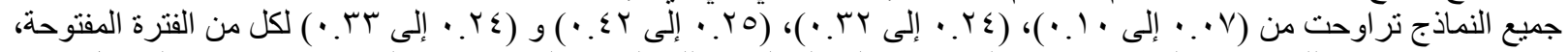

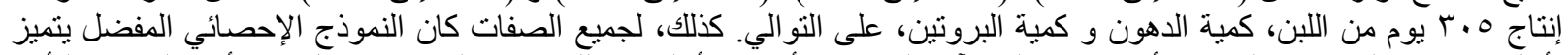

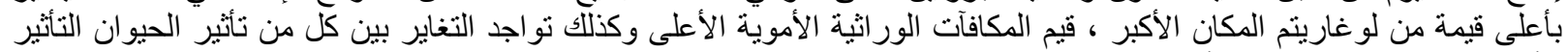

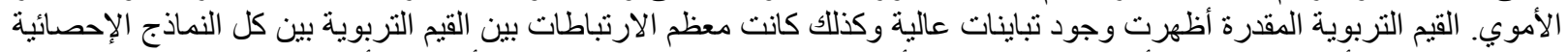

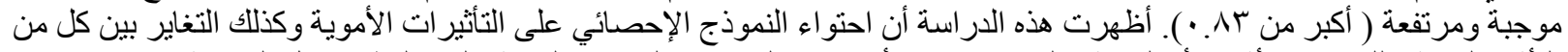

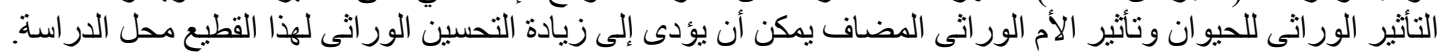

